Hizli Alkan, S. \& Priestley, M. (in press). Teacher mediation of curriculum making: the role of reflexivity. Journal of Curriculum Studies

\title{
Teacher mediation of curriculum making: the role of reflexivity
}

\author{
Sinem Hizli Alkan ${ }^{\mathrm{a} *}$ and Mark Priestley ${ }^{\mathrm{b}}$ \\ ${ }^{a * b}$ Faculty of Social Sciences, University of Stirling, Stirling, Scotland \\ ORCID $^{\text {a*: }}$ https://orcid.org/0000-0003-0694-4160 \\ e-mail ${ }^{a *}:$ sinem.hizliaalkan1@stir.ac.uk twitter: @SinemHizli \\ ORCID $^{\text {b }}$ https://orcid.org/0000-0001-8276-7771 \\ e-mail ${ }^{b}$ :m.r.priestley@stir.ac.uk twitter: @MarkRPriestley
}

Wordcount: 11046

This is an Accepted Manuscript of an article published by Taylor \& Francis Group in Journal of Curriculum Studies on 02 Jul 2019, available online:

http://www.tandfonline.com/10.1080/00220272.2019.1637943 


\section{Teacher mediation of curriculum making: the role of reflexivity}

This research explores curriculum making by teachers and offers a nuanced way of understanding these practices through the concept of reflexivity. The study draws from a collective case study of teachers in an online focus group, in order to identify and analyse diverse thinking on the curriculum by teachers from Scotland and Wales. A WordPress ${ }^{\circledR}$ page was set up to generate both synchronous and asynchronous discussions over a period of five weeks to discuss curricular issues. Six teachers from Scotland and three teachers from Wales participated in the discussions. Data collection tools comprised iteratively designed interview questions and an Internal Conversation Indicator (ICONI), for indicating participants' dominant mode of reflexivity. Data were analysed thematically, drawing from Margaret Archer's theoretical constructs relating to reflexivity and internal conversation. Data analysis suggests that reflexivity provides a useful lens for understanding teachers' particular approaches to curriculum making. The research suggests that curriculum making practices can be understood, at least partially, in relation to different modes of reflexivity. Further research is needed to substantiate these arguments and provide richer picture of curriculum making.

Keywords: curriculum making, reflexivity, teacher agency, Scotland, Wales

\section{Introduction}

In recent years, there has been an increasing interest in curriculum, including discussions on the role of teachers in curriculum making (Kontovuorki et al.,, 2018; Pyhältö et al., 2015; Wallace \& Priestley, 2017). This 'renaissance' (Priestley \& Biesta, 2013, p.3) of the curriculum is rooted to some extent in the emergence of new policy forms in many countries - a 'new curriculum' (Priestley \& Biesta, 2013, p.2) - with a strong emphasis on 21st century skills and competences, shaped by global influences (e.g. international tests). According to Sinnema and Aitken (2013), the 'new curriculum' is characterised by a number of common goals (school improvement, equity, a future focus and coherence) explicitly framed to address economic, technological and social changes. These new forms of curriculum can be seen to a large extent as explicit responses to a series of worldwide challenges facing societies, formulated recently by the OECD as environmental, economic and social (OECD, 2018).

The emergence of 'the new model of curriculum' demands different input from actors at different levels or layers of educational systems - macro (national level), micro (school level), with a particular focus on schools as sites for curriculum making (e.g. see Priestley \& 
Philippou, 2018; van den Akker, 2003). More explicitly, curriculum making, as a process of interaction between different actors within the education system, occurs at different layers in interaction and intersection with one another (Priestley \& Philippou, 2018), and this underlines the important role of teachers as active curriculum makers in their schools and classrooms.

These new curricular frameworks illustrate a shift away from input regulation (e.g. tight prescription of content; see Nieveen \& Kuiper, 2012) towards more flexible designs around key competencies and/or big ideas approach, which allow schools and teachers greater space for manoeuvre in curriculum making to address local needs (Priestley et al., 2012). Scotland and Wales, which provide the contexts for this study, are good examples of such a tendency, both having developed curricula that explicitly require teachers to actively engage in curriculum making to bring about educational change. This new approach to curriculum may, however, bring new challenges for teachers, as there are a number of factors which may affect teachers' engagement with policy. For instance, they may develop interpretations of core concepts (e.g. active learning, interdisciplinarity, etc.) that diverge significantly from policy intentions, or even fail to develop understanding of these in an absence of clear and grounded guidance and structured opportunities for shared sense-making (e.g. Pietarinen et al.,2017; Wallace \& Priestley, 2017). This may lead them to continue with their old habits and understandings regarding curriculum making (Priestley et al., 2015). These factors (and others) are subject to mediation by teachers engaging in curriculum making.

Building upon the previous literature on the relationship between teachers and curriculum making, we aim to address the mediation by teachers of the factors that shape curriculum making, using reflexivity as a theoretical lens. This paper addresses following research questions:

1. In what ways do teachers conceptualise curriculum and curriculum making?

2. What are the personal, structural and cultural factors which influence curriculum making?

3. How do teachers mediate these factors in their curriculum making practices through reflexivity?

\section{Contexts: Scotland and Wales}


We begin by providing an overview of two contexts, Scotland and Wales, where the historical background and current curriculum reforms manifest characteristics which are both similar and different.

\section{Scotland - Curriculum for Excellence}

The Scottish Curriculum for Excellence (CfE) was formally implemented in 2010 after a period of discussion, guidance, reflection and developments, following the publication of the policy documents by the Scottish Executive in 2004. CfE is framed by three elements $\left.{ }^{1}: 1\right]$ four capacities, general competences which are presented as the purposes of the curriculum; 2] seven principles of curriculum design; and 3] eight curriculum areas, which are articulated through a large number of experiences and outcomes (Es and Os), set out in sequential levels (Education Scotland, 2016). These Es and Os are less prescriptive and specific in content than the learning outcomes of previous 5-14 curriculum (Priestley \& Minty, 2013), and thus offer more scope for adaptation to local needs by schools, demanding professional capacity in curriculum making. Indeed the new curriculum presents teachers as being the primary agents of change, in what is often presented as being the most significant reform in Scottish Education in a generation; one that 'aims to engage teachers in thinking from first principles about their educational aims and values and their classroom practice [...] through a climate in which reflective practitioners share and develop ideas' (Scottish Executive, 2006, p.4). The fundamental argument was that many curricular decisions are best made in their local contexts.

These aspirations have subsequently proved hard to realise both methodologically and philosophically. For example, detailed specification of learning outcomes, the structuring the curriculum as established subjects, and the elaboration of the curricular purposes set out in the Four Capacities have introduced ambiguity in curriculum making processes, eliciting criticism that $\mathrm{CfE}$ has established multiple starting points for curriculum making that sit in tension with one another (Priestley \& Humes, 2010). Research also suggest teachers' engagement in school-based curriculum making has generally been limited by the continued emphasis in the Scottish system of intrusive accountability practices (e.g. Priestley, 2014; Wallace \& Priestley, 2017) and by hierarchical cultures where teachers may not see active curriculum making as their responsibility (Priestley et al., 2015). The nature of the change process - extensive and not always coherent written guidance from national agencies and

\footnotetext{
${ }^{1}$ Further details on these elements can be found here: https://bit.ly/2iXHX9h
} 
local authorities being the main form of support - has tended to neglect formal sense-making processes undertaken by teachers, leading to uncertainty and a lack of progress in transforming practices at school level (Wallace \& Priestley, 2017).

\section{Wales-The Curriculum for Wales}

At the time of writing the new Curriculum of Wales is still under development; specifications are being developed for implementation in 2022 following a pilot phase in 'pioneer schools' (Education Wales, 2017). These schools are working collaboratively to develop curriculum policy, with input by a variety of national and international expert groups (e.g. Estyn ${ }^{2}$, Curriculum and Assessment Group). The curriculum is structured similarly to CfE in Scotland, around three elements ${ }^{3}$ : four purposes; principles of curriculum design; and six Areas of Learning and Experiences (AoLEs).

The overall rationale of the curriculum is presented in relation to the four main purposes and principles recommended by Graham Donaldson (2015), who previously led a review of teacher professional learning for CfE in Scotland (Donaldson, 2011). Similarities to Scotland's curriculum, and the genesis of its seminal report have led to accusations that it is simply a carbon copy of a curriculum that is claimed by some to be unsuccessful in its original setting (e.g. Old, 2015). Nevertheless, since its inception the Curriculum for Wales has evolved, and it diverges in some important respects from its Scottish counterpart. AoLEs have been framed around big ideas called What Matters statements (Welsh Government, 2017). Each of these is accompanied by progression narratives and statements of learning outcomes are likely to have a minimal presence in the new curriculum. An additional feature is the presence of Knowledge, Skills and Experiences (KSEs) - broad statements of indicative knowledge, skills and experience for each What Matters statement - which provide some general specification of content to guide schools, and which indicate a focus on the importance of knowledge. This latter emphasis goes some way to addressing the regular critique that this type technical/rational curriculum downgrades knowledge (see for example Priestley \& Sinnema, 2014; Wheelahan, 2010; Yates \& Collins, 2010; Young \& Muller, 2010). Notable, also, in the Welsh case is the explicit emphasis that the Curriculum for Wales is a purposes-led curriculum; this means that subsequent specification has been written with strong links to the Four Purposes, and it is intended that school curriculum making practices

\footnotetext{
${ }^{2}$ Estyn is the Welsh schools inspectorate (see https://www.estyn.gov.wales/language).

${ }^{3}$ Further details on these elements can be found here: https://beta.gov.wales/new-curriculum
} 
will have, as their primary reference point, these purposes. The detailed elaboration and specification for the curriculum has been largely produced by groups of teachers from the pioneer schools, supported by a range of experts and education professionals (e.g. Qualifications Wales). This model has been criticised for excluding non-pioneer school teachers (e.g. Arad Research \& ICF Consulting, 2018), nevertheless, teacher involvement in curricular policy making has been extensive in comparison with Scotland, and is an explicit intention that schools and teachers will be afforded more scope than previously to use their professional knowledge in curriculum making, to adapt the curriculum to local contexts (Education Wales, 2017), as in Scotland. Previously, the National Curriculum inhibited teachers' freedom due to prescribed syllabuses, centralized control and accountability systems (McCulloch, 2000).

Overall, the differences in Wales, in terms of the framing of the curriculum and the co-construction processes, seem likely to lead different practices, in comparison with Scotland. Two key factors are the creation of different starting points for school level curriculum making and greater opportunities for sense-making among teachers, which can play a key role in meaningful curriculum reform (Pyhältö et al., 2018; Soini et al., 2017).

\section{Teachers and curriculum making}

The term curriculum making was first mentioned by Bobbitt around a century ago (2009; see also Bobbitt, 1924, cited in Scott, 2008). It has subsequently been utilised in various different studies, for example Bloomer (1997), and has often been used interchangeably with curriculum development, for example by Stenhouse (1975). In Bobbitt's approach, curriculum making was understood as a 'linear process to the selection of content, which starts with the development of clear objectives or goals, proceeds to the selection of content which is specified in behavioural terms - that is, its acquisition must be an observable or testable process - and finishes with the evaluation of that process to see if those objectives have been met' (Scott, 2008, p.7). We see similar usage in Tyler's rationale (1949). The role of teacher was therefore to deliver a curriculum, which was 'discovered' by curriculum professionals based on scientific methods to decide behavioural objectives.

After the work of Bobbitt and Tyler, which we would argue imply a limited conception of curriculum, Schwab claimed that curriculum studies are moribund due to the over reliance of theory (Schwab, 2009). He proposed a participatory approach to curriculum decision making and understood curriculum making as the vital processes of the deliberate 
Hizli Alkan, S. \& Priestley, M. (in press). Teacher mediation of curriculum making: the role of reflexivity. Journal of Curriculum Studies

engagement of 'real actors', underlining the importance of practice, local thinking and the ownership of teachers. This accords with the earlier work of Dewey (1938), which emphasised the active involvement of teachers in curriculum making. He posited curriculum making as a reconstruction of the inherited cultural wisdom with children through inquiry, and the teacher was thus seen as a central curriculum maker in such reconstruction processes (Dewey, 1938).

Similarly, Bloomer's (1997) work on curriculum making in Higher Education supported the idea of teacher and student agency and the need for a reconceptualization of knowledge, learners and the context, emphasising the social aspects of each. This understanding of curriculum making is as 'a heuristic process heavily dependent upon the participation of those who it is intended will be affected by it.' (ibid., p.188). Such participation was also Stenhouse's (1975) core argument. He perceived teachers as researchers and stated that there is no curriculum development without teacher development.

This study builds upon these valuable ideas and offers a different lens, reflexivity, to examine curriculum making, where teachers are integral part of such processes in their unique contextual characteristics. In fact, the separation of teacher and curriculum is argued to be fictional considering the complex, multi-layered and intersected social practices of teaching and teachers, which are unpredictable (Kontovourki, Philippou \& Theodorou, 2018). This organic relationship means that the enactment of curriculum may be influenced by and influential on teachers as individual professionals who have their own orientations and distinctive sense-making processes (Troyer, 2019). Teacher agency is therefore an important concept here, as teachers interpret, mediate, and translate policies in different ways; in short, teachers do not implement policy, but instead enact it (Ball et al., 2012; Coburn, 2005; Spillane, 1999). Teachers' curriculum agency is equally important which can be examined at collective space, individual space and interactive space in classrooms (Alvunger, 2018). Existing research (Priestley et al., 2015; Pyhältö et al., 2015; Wallace \& Priestley, 2017) illustrates that teacher agency can lead to different practices, which can diverge from what the reforms and policies initially intended (Cuban, 1998).

This enactment of curriculum has been examined at different levels and through different lenses. For example, it has been suggested that curriculum materials mandated through macro level reform were strategically transformed, mainly through reading (e.g. focusing on the general outline of a lesson), evaluating (e.g. focusing on students) and 
adapting the activities or materials (Sherin \& Drake, 2009), usually in response to perceived student needs or the requisites of local curriculum reform pressures (Burkhauser \& Lesaux, 2017). During school level curriculum making, teachers may lack curriculum design expertise, pedagogical content knowledge and curricular consistency expertise (Huizinga et al., 2014), which may hinder the reform aims. Hence, 'teachers matter in spaces where they can act as moral subjects in their profession in the present, drawing on collective and individual experiences of the past while imagining a desired future' (Alvunger et al., 2017, p.3), which accords with the definition of reflexivity, unpacked in the following section.

\section{Theoretical Framework}

The theoretical framework is drawn from Archer (2003). She defines reflexivity as 'the regular exercise of the mental ability, shared by all normal people, to consider themselves in relation to their social contexts and vice versa' (Archer, 2007, p.4). According to Archer, we all have internal conversations in considering our concerns and priorities, in order to shape and decide future/further actions. Reflexivity is an important concept in curriculum studies for at least three reasons. Firstly, it leads teachers to ask, 'what matters' and 'what to do next' (Willis et al., 2017, p. 795), which helps them to navigate through a complex world in a time of ongoing reforms, accountability, diversity and community expectations (Ryan \& Bourke, 2013). Secondly, it is important because different modes of reflexivity (Archer, 2007) shape engagement with social issues in different ways, which may shed light on the myriad ways of mediating curriculum making practices at school level. Thirdly, reflexivity has the potential to build on the notion of reflective practitioner (Schön, 1983), foregrounding this concept as an important element of reflexivity in the mediation of curriculum making practices.

Archer (2007) proposes a typology of four modes of reflexivity, based on her empirical research: communicative reflexivity, autonomous reflexivity, meta-reflexivity and fractured reflexivity. This typology helps us to understand diverse forms of action. People who exhibit communicative reflexivity tend to need affirmation through an external dialogue with others prior to action. Autonomous reflexivity manifests as self-contained internal conversations, which lead to taking action. Meta-reflexivity is depicted as reflecting on one's own actions and engaging in continuous self-evaluation. People who demonstrate fractured reflexivity appear to intensify their personal distress and social orientation in the face of complexity. 
However, one needs to approach these classifications with a caveat, as reflexivity is a contextual and multifaceted activity (Archer, 2007). For example, the literature offers some examples where participants practise provisional reflexive modes in addition to or alongside their dominant mode of reflexivity (Brew et al., 2017; Kahn et al., 2017; Wimalasena, 2017). Hence, the mode of reflexivity is not understood as deterministic and fixed, but rather as a nuanced way of understanding individuals' actions (Wimalasena, 2017). Thus we prefer to use the terms 'exhibit/demonstrate/practise a mode of reflexivity', rather than labelling individuals as one mode of reflexive or even reducing reflexivity to personality types (Archer, 2007).

\section{Research Design}

The study is a collective case study (Stake, 2005), as there is less interest in one particular participant, but rather in the collective phenomena evident across the practices of a group of teachers. The primary aim was to better understand the social phenomena in terms of emerging concepts, themes and processes.

\section{Context}

An online focus group was selected for generating data, including teachers from Scotland and Wales, during 2018. Focus groups offer a space for observing diverse opinions from different participants, who are sometimes difficult to reach (Gaiser, 2008). In this study, the method was chosen for its potential to portray examples of curriculum making practices from two geographically separated contexts. However, online focus groups are sometimes questioned for their focus group characteristics in terms of narrowing interactions (Stewart \& Williams, 2005). For example, the questions set for each week might lead teachers to answer these questions, more than activating an interaction among all teachers (Murray, 1997). In order to address this issue, we linked the responses from different participants to trigger further interactions. Besides, there are also some benefits which outweighed this issue. For example, online space where people are anonymous creates a safe and comfortable environment to express their thoughts (Stewart \& Williams, 2015), while also allowing time for participants to provide more depth and substantive responses (Gaiser, 2008).

A WordPress ${ }^{\circledR}$ page was set as an interface, enabling both synchronous and asynchronous discussions. The WordPress ${ }^{\circledR}$ site was chosen as a viable alternative to the traditional focus groups (Hancock, 2017), being easy, free and secure to use. Synchronous discussions took place on a specific day and time slot in the first week. This was the time 
when teachers were most active. During asynchronous discussions, teachers made links to the previous discussions and created new discussion threads.

\section{Participants}

Teachers were recruited using opportunistic sampling through an advertisement via social media (Twitter) and professional networks (e.g. through university programmes). The main inclusion criteria were teaching permanently in a school and agreeing to participate for at least half an hour per week. Three teachers from Wales and six teachers from Scotland, from a range of different backgrounds and with different levels of experience, participated actively in the online discussion forum for five weeks. For example, two teachers had more than 20 years of teaching experience. Both primary and secondary school teachers participated and some of them were leading curriculum development processes in their schools.

\section{Instruments}

Some concepts (e.g. priorities, values, enablers in curriculum making, etc.) from the related literature were utilised to design a flexible topic guide, which was revisited each week following the online discussion. In the final week of the research, teachers were asked to complete the Internal Conversation Indicator (ICONI) questionnaire (Archer, 2008). This was developed by means of quantitative and qualitative research with different samples to indicate the dominant mode of reflexivity, and was utilised by Archer as a sampling device to further investigate the modes of reflexivity, with interviews being the major sources to define the modes of reflexivity. In our research, ICONI was employed to indicate teachers' dominant modes of reflexivity and to enrich the dataset in terms of having more sensitizing concepts to make sense of the data; this in turn assisted the final stage of data analysis, considering the characteristics of each modality. Since the scores only increase the probability of these dominant modes (Archer, 2007), attribution of the modes of reflexivity (dominant and relational) was finalised after obtaining the results of ICONI and interpreting the transcripts.

\section{Reflexivity of Researchers}

Reflexivity as a dynamic, ongoing and evolving process (Clark \& Dervin, 2014) of selfprojection and self-awareness (Finlay \& Gough, 2003) was also an essential part of how we designed and conducted the research while being aware of the interconnectivity between us, the participants, the data and the method we used (Deborah \& Banister, 2012). We give a few examples following different stages of research activities. Before online discussion; we were 
both aware of the way we accessed participants, which may (or not) had an influence on the kinds of discussions. For example, many of the participants were active on the social media platform where we advertised the research, and follow one of the researchers' work, which elicited comment in the online discussion (e.g. teacher agency). During online discussion, one of the researchers was responsible for moderation of the conversations. There were spontaneous decision making processes on when to add prompts and how to integrate multiple comments to support structured and systematic interactions.

Since most of the data generation and analysis was done concurrently, we had discussions on the diagrams and hierarchies of emerging themes and in what ways relational reflexivity modes could enrich the findings. These discussions and decisions on the next steps were recorded as notes. Alongside these interactions and discussions, the analysis of data was completed by one of the researchers, which we explain in detail in the next section.

\section{Data analysis}

Lincoln and Guba's (1985) criteria for trustworthiness (credibility, transferability, dependability, and confirmability) are employed in order to offer a detailed account on this procedure.

Thematic analysis was employed to explore teachers' understandings of curriculum and curriculum making inductively using open coding derived from the literature. To address credibility, peer debriefings were held to discuss if the views of teachers and whether the representation of them as themes would fit. For example, structural and cultural factors were a key point of our discussions. We agreed to use research questions and, as mentioned earlier, Archer's theoretical constructs and particularly reflexivity as starting points for the next step analysis. Data were coded under these themes and organised in two groups: enablers and constraints. For instance, if a cultural factor was considered to 'make desired actions easy to accomplish' it was coded under the enabler factor (Archer, 2007, p.215).

Related to generalization of findings, Mason (2002) argues that there are two distinct ways: empirical and theoretical generalization. Empirical generalization, which is not attempted in this research, is based on generalization of the empirical findings to a larger population. This research, alternatively, claims theoretical generalization for achieving a wider resonance on the reflexivity to shed light into curriculum making by teachers. Moreover, instead of empirical generalization, transferability should be considered by the 
reader on the basis of the extensive descriptions of the context and findings (Lincoln \& Guba, 1985).

\section{Ethics}

The ethical guidelines of British Education Research Association (BERA, 2018) were applied in this research. More specifically, non-traceability was facilitated by assigning pseudonyms at two stages; for the online discussion and for this paper. In order to further minimise the potential risk of harm, 'Netiquette' (Eynon et al., 2011) protocols were agreed by all teachers, regarding sharing respectfully and protecting privacy. The online discussion forum was set as private, and only invited teachers could access it, after sending their signed informed consent forms. The data were protected in compliance with the data management protocols of the University of Stirling.

\section{Findings}

\section{Conceptualisation of curriculum and curriculum making}

The concept of curriculum and curriculum making were understood in different ways and at different levels by teachers. Based on the transcriptions, curriculum was conceptualised as focusing on the content, the product and the process, with some overlaps which is in line with Kelly's (2004) distinction of different starting points for curriculum planning. Some of the common responses in curriculum as content covered a 'group of subjects to teach' (Arthur, Scotland) or a 'mechanical framework for ensuring that learners develop skills and knowledge to connect their society' (Jack, Wales). In the process-focused conceptualisation of curriculum, it was evident that some teachers focused on the nature of the learner and principles of the educational aims. For example:

Curriculum to me is a pupil centred curriculum that is broad and balanced. With literacy and numeracy at the forefront...Being Welsh, I would also like it to be linked as much as possible to Welsh culture, history and geography and how Wales is linked to the wider world. (Oscar, Wales)

The focus on the curriculum as product revealed a more technicist approach, illustrated in comments such as 'curriculum should be the outline of the learning goals' (Henry, Wales) and 'curriculum is an imposition of workload from distant and unaccountable figures' (Kevin, Scotland). Although Kevin defined curriculum based on his reactions to the new curriculum reform in his context, at some point he commented that curriculum should be 
based on broad aims, principles and pedagogical approaches proven to work. Hence, personal opinions on curriculum seemed to be mediated by his contextual conditions, which will be further explored in the final section.

As for curriculum making, teachers identified different levels such as macro (national), meso (school) and micro (classroom) throughout the discussion (see for example van den Akker, 2003). And, although there were different ways of conceptualising curriculum, there seemed to be agreement on having the national and the local dimensions of curriculum making.

\section{Factors mediate curriculum making}

We now discuss three factors that mediate curriculum making practices: individual, structural and cultural factors.

\section{Individual factors in curriculum making}

Each factor has both specific and overlapping attributes with other factors. For example, some teachers' responses, such as a willingness to cooperate, having previous experience in curriculum making, job satisfaction and beliefs towards being able to achieve agency, could function as enabling factors, whereas feeling mistrustful to the government, lack of motivation and believing that their agency is hindered by several factors might constrain their curriculum making practices. Not surprisingly, teacher agency was cited as both enabler and constraint. For instance, Henry emphasised how achieving agency enabled curriculum making practices, by emphasising the emerging phenomena aspect of teacher agency (see Priestley et al., 2015)

I have had great teaching and learning experiences in the past when I have had the freedom to develop cross curricular units of work, starting from the interests of the children within the context of a broad curriculum framework. That is where my artistry has come into play developing interesting, meaningful context for learning which engage the learners. (Henry, Wales)

However, some of teachers stated that if a teacher has a lack of agency, 'they want to be told exactly what, when and how to do it' (Arthur, Scotland), which in turn constrains curriculum making practices. This reflects, the capacity aspect of teacher agency (Priestley et al., 2015). Besides this, there are other factors which inhibit agency even though teachers 
have the capacity and would like to exercise agency. These factors, such as accountability and assessment systems, are explored more in the structural factors section.

Teachers with an interest in reading educational research, who follow current discussions around new reforms, seemed to nurture their curriculum making practices. For example, one teacher stated that:

I have a particular interest in looking at research in education and how it can be utilised in the classroom. (Kevin, Scotland)

Whereas another commented:

Teachers need to engage with research and academic reading more, and with ideas rather than forms and tables and grids. (Sam, Scotland)

Therefore, engaging with research may be perceived as a way of fostering agency in curriculum making.

The way that teachers feel about their job and pupils was another individual factor, which could hinder or activate curriculum making practices. For instance, when a teacher enjoys what they do, they tend to put more time and energy on doing things as illustrated in the following statement:

I thoroughly enjoy my job, and get an enormous amount of job satisfaction from getting students through an exam or a topic that they originally struggled with. I find that a large number of students find maths 'boring' and I try to make maths a little bit magical. (Beth, Scotland)

\section{Structural factors in curriculum making}

Structural factors were addressed throughout the research period in the different discussion topics. As is the case for the individual factors, enablers and constraints were also evident. The data suggested that accountability and examination systems, political agendas, lack of time, poor collaboration, hierarchy, poor leadership and the catchment area of schools tended to constrain curriculum making practices. In particular, accountability was observed to be one of the prominent constraining factors in curriculum making throughout the research, among all teachers. This is interrogated from different perspectives, which in turn seem to point to potential tensions, for instance, tensions between flexibility and accountability, disbelief towards the necessity of paperwork and accountability, policy compliance and accountability and time-related issues and accountability. Some tensions seem to be 
intertwined with cultural factors in curriculum making. For example, disbelief towards the necessity of paperwork as an accountability practice is illustrated here:

The least favourite things about my job is when I am asked to supply data or fill in forms and then find this information is only a process and not used for any meaningful improvements. (Arthur, Scotland)

One teacher, with a background of working in England for years with the National Curriculum (known for its prescriptive structure) offered a different perspective on accountability. He stated:

The accountability was not a problem, as the school I was working at during that period had been given the 'power to innovate' which gave us the official nod to explore possibilities, yet we still developed a very clear and accountable curriculum structure, planning structure and assessment mapping with enough flexible to start each unit of work with pupil voice. (Henry, Wales)

Hence, accountability itself may not be an inhibitor. Rather it is required to be activated through the other factors which hinder teacher agency.

In the enabling structural factors, leadership and professional dialogue were often mentioned as the strongest factors to mediate curriculum making practices. There seemed to be consensus about the significance of head teachers' leadership skills which might strengthen teachers' experience in curriculum making. For instance, one participant from Wales stated that:

At this moment we have pioneer schools working on the 'what' statements for our new curriculum and if those pioneer schools have inspiration leadership it will produce something inspirational but if not then those 'what' statements could be stifling. (Oscar, Wales)

Some of these factors (e.g. leadership) also have cultural elements, which act to reinforce each other, and these will be discussed in the next section.

\section{Cultural factors in curriculum making}

Cultural factors are mainly related to ideational components (Archer, 2003). For instance, shared beliefs and values, reciprocity and vision were stated as enablers to mediate curriculum making practices whereas attitudes to change, non-generative dialogue, policy compliance and disbelief towards the necessity of paperwork were indicated as constraints. 
An example of vision and reciprocity is evident in the following comment on transition issues:

I have suggested that the Maths teachers go into the primary schools and teach some areas. There is a numeracy programme being used in primary schools, but the current s1s (the first group who have followed CfE all the way through) have not seen the benefit...We know where the students should be in S1, and it makes more sense for us to go them, rather than to dictate where the students should be. (Beth, Scotland)

Another enabler factor, shared beliefs and values, was mentioned with regards to leadership, yet was approached from an ideational angle. It was stated by one teacher that school leaders sometimes need to have difficult conversations with external agencies to stand up for what they believe is right for their school. However, some teachers agreed that this kind of leadership is 'sadly' rare nowadays due to dramatic changes in bureaucracy, or in other cases it appears that some of them have their own curriculum agenda which leaves limited room for teachers to act differently. Nevertheless, teachers from Wales seemed to be relatively more optimistic about the near future developments, because they agreed that creating a schools' leadership programme alongside the new curriculum was a good idea. The problematic issue for them seemed to be the external collaborations which were taking place whilst making the curriculum. The pioneer school approach had been questioned throughout the discussions in terms of the dissemination of the information, the inclusiveness of its approach and limited opportunities of collaboration.

In summary, the aforementioned factors potentially influence how teachers engage with the curriculum. In the next section, we provide a discussion on how teachers mediate these factors in curriculum making practices with respect to reflexivity.

\section{Mediation of these factors and reflexivity}

It should be noted that these factors (and potentially more) mediate curriculum making practices, but do not entirely determine these practices (Mouzelis, 2007). These factors are important in foregrounding the key issue in this research, but incomplete as they are not embedded with reflexivity. The fundamental aim of reflexivity is to outline a modus vivendi which is satisfying and sustainable as a result of mediation of these factors. Each mode of reflexivity, which is mutable, has a distinctive way of navigating structural and cultural enablers and constrains based on the subjects' subjective projects in relation to the objective circumstances (Archer, 2003). As indicated previously, investigating reflexivity is a 
multifaceted and complex activity and therefore the results of the ICONI and the transcriptions are used as a starting point to make sense of the data. The dominant modalities are based on teachers' subjective explanations, which are always fallible so there is no claim to be made that these reflect the actual reality. Nevertheless, they illustrate different ways of thinking and reasoning on curriculum making in different contexts.

In order to portray this complex process, we present four cases which strongly illustrate the characteristics of different modes of reflexivity based on the ICONI results and the interpretations of the transcripts. We suggest that teachers' responses are mediated by the modes of reflexivity they exhibit.

\section{Communicative Reflexivity}

Based on the results of ICONI, there were three teachers who exhibited communicative reflexivity as the dominant mode, and one having autonomous modality alongside. One case is presented here as the data reflect relatively strong aspects of this particular mode, based both on the ICONI score and on transcripts.

Henry has worked as a primary teacher and latterly a deputy head in Wales for 20 years, with 15 of these in different leadership roles. He worked in England until 15 years ago, but decided to move because he believed that professional freedom has been lost there. He thoroughly enjoyed working as a teacher and a deputy head, which he believed gave credibility to his decisions. As appeared to be the case for all of the teachers, evidence gathering was the least favourite part of his job, as he thought these activities can often distract teachers from focusing on teaching and learning.

He seemed to be concerned about the direction of the current curriculum reform in Wales, due to what he saw as the unclear guidance and only partially inclusive approach to curriculum making. Even though he appreciated the intentions of Welsh Government at this stage, he thought that there was a potentially widening gap between pioneer schools and the rest of the school population. For instance, he sought tangible examples from pioneer schools and more guidance from local authorities and/or Welsh Government on his school's curriculum making practices. This seems to be one of the common attributes among people who practise communicative reflexivity. Henry was seeking affirmation as to whether his school was keeping on the right track or not. Archer explains this pattern as 'a need to share thoughts with others in order to conclude their deliberations' (Archer, 2007, p. 102). This pattern may also come into play in his work as a both teacher and deputy head teacher in this 
specific time period. Archer adds that it does not mean those who exercise communicative reflexivity are not able 'to initiate a train of reflexive thought when alone' (p.102). This also appears in this case; that even though Henry was seeking to affirmation and assurance from others, he initiated his school to move on, in line with the national mission statements, after obtaining tangible examples.

Henry emphasised the significance of shared expertise, internal collaborations in the school and mobilising the power of all school staff to have an input into the direction of the curriculum. Parallel to this thinking, he participated in a number of conferences where Welsh Government updates and reports were presented, in order to make better sense of the current reforms. The prominent enabler in curriculum making for him was having teachers involved actively and coherently in the development of curriculum.

At the same time, he was critical of the Regional Consortia for promoting their own approaches to curriculum, as he thought it could stifle creativity. Hence, inner deliberations appeared to be open to selective scrutiny (Archer, 2007).

Viewing reflexivity as context dependent, it could be further argued that Henry was practising meta-reflexivity alongside the dominant modality of communicative reflexivity. He was challenging the status quo and demonstrated a deep concern for equity. He was also supportive of the idea that one of the greatest enablers in the curriculum making process is having strong leaders who are willing to stand up for what they believe is important for their schools, even though it may elicit difficulties with external agencies. Structural (e.g. location of a school) and cultural factors (e.g. vision) seem to reinforce the patterns of this modality.

If you happen to live near a school where they have been involved in the Pioneer Programme or if the school has a Head Teacher who has contacts in the LA and other institutions then you may get a more innovative curriculum, than those schools left on the fringes of the curriculum reform and who appear to constantly be playing catch-up with those schools who are deemed 'excellent'. (Henry, Wales)

We argue that, since schools in Wales are still in the construction phase for the new curriculum, teachers tended to seek clear guidance and support through internal and external collaborations to navigate their way through complexity, as was the case with Henry. His will to collaborate with wider stakeholders might nurture this process, yet some of the structural factors (e.g. poor collaboration) seemed to hinder his achievement of a satisfactory modus vivendi. What he did, as a person establishing communicative reflexivity, was to turn to his 
immediate colleagues to develop a sense of contentment and to finish his inconclusive internal conversations at a micro-level. This modality enabled to share expertise and encouraged to secure maximum benefits from the available support mechanisms. However, the future steps in the current reform should be taken with adequate caution, in terms of providing thorough guidance as well as opportunities for fully inclusive and constructive debate. Nevertheless, the pioneer approach in Wales is promising a teacher-led and relatively inclusive approach; however it appears that, since teachers tend to be action-oriented, it will take time for them to get used to a more nuanced approach to curriculum making based around reflection, dialogue and collaboration (Drew, Priestley \& Michael, 2016).

\section{Autonomous Reflexivity}

The only individual who exhibited autonomous reflexivity as the dominant mode is presented here to provide insights on how this mode of reflexivity may mediate curriculum making practices. Edward had the highest score and demonstrated an inclination towards this modality on qualitative grounds.

Edward has been teaching for 17 years in different positions, including working with the Scottish Qualifications Authority (SQA), and was working in a provincial rural school at the time of the research. He indicated that he is genuinely interested in curriculum.

He was concerned mainly about the decision making process at macro and microlevel and the benchmarks of CfE. He claimed that decisions are often made with considerably little input from teachers in secondary level, without considering their values, concerns and thoughts about the students' journey. The decisions at micro-level are also 'indefensible decisions', such as prioritising Advanced Higher ${ }^{4}$ classes over small National 4 classes, due to the lack of time, limited resources and staff. As a person who exhibited autonomous reflexivity as a dominant mode, he seemed to have a clear sense of what he can control and influence. Hence, he mostly emphasised that his feelings and opinions are his own, which shows sustainment of self-contained internal conversations. He believed it was his personal responsibility to navigate his way through the curriculum, which is a common personal trait in this modality.

\footnotetext{
${ }^{4}$ Further information on the qualifications can be found here: https://scqf.org.uk/
} 
Most of the teachers from Scotland argued that there is less appetite for flexibility, for several reasons. Edward proposed that this could be reworked to create potential success using the curriculum or by other capacity building means. He saw $\mathrm{CfE}$ as giving permission to be creative to those teachers who would like to foster their agency or as sufficiently prescriptive for those who have less desire to engage with it. This approach can also be seen as a typical of autonomous reflexivity; self-confidence in his mental judgements and the structural enablers and constraints. Archer (2007) perceives such circumstances as 'instrumental rationality', where people's orientation is towards a specified end, in this case reaching the potential of $\mathrm{CfE}$.

Exhibiting autonomous reflexivity does not mean that teachers do not consider other people's opinions (Archer, 2007). Even though Edward seemed to prioritise his own mental resources, he was suggesting the involvement of subject experts for informed debate in macro-level curriculum making. This resonates with the characteristics of autonomous reflexivity, which is to prefer expert advice if supplementing is required. Nevertheless, we argue that some of the characteristics of meta-reflexivity could be observed in his transcripts as well through his evaluations of internal deliberations.

I'm still not sure how I would know if I am successfully engaged. I try to negotiate a difficult line between school curricular structure, time constraints, the needs of the pupils and assessment and tracking demands. It's a contested area and extremely difficult to service all stake holders. (Edward, Scotland)

Edward appeared to feel responsible personally for his choices and actions; while he thought the key to potential success in curriculum making is providing opportunities to reach the potential of $\mathrm{CfE}$ and being listened and trusted, he tended to be more task-oriented. We could speculate that his experiences in the SQA and the language he preferred (underlining qualifications) might be associated with his dominant mode of reflexivity, which would direct him to shape his curriculum making practices in line with the performative achievement criteria. Such strategies could be used to activate the enablements in the education system in a strategic way, which is one of the distinctive characteristics of this modality.

\section{Meta-reflexivity}

There were four teachers who exhibited meta-reflexivity as the dominant mode in this study. Deciding on one which best illustrates the common characteristics of this modality was difficult, as they all showed strong features. This is not very surprising considering that every 
person exercises this modality at least on occasion (Archer, 2003). Nevertheless, one case was selected, as it has the potential to reflect most of the common attributes of this mode, and also had the maximum score of seven from the ICONI.

Amy was a senior leader in a secondary school in rural Scotland, with 21 years of experience including some in English schools, similar to Henry. She noted right from the beginning that she loves her job, because she has the chance to potentially 'change the world for the better'. This key mantra of meta-reflexivity is explored further below.

Macro-level decision making was one of her concerns related to curriculum, as she thought this was often based on political ideas, rather than coming from teachers or other experts planning strategically. She frequently stated that her decisions are 'absolutely driven by values and students' needs'. This is a typical characteristic of those who practise metareflexivity, as they tend to be values-oriented (Archer, 2007). However, this does not mean that they are always successful in achieving their goals. For example, Amy mentioned how staffing and continuous change from the SQA and government seems to inhibit her from living up to her ideals. This is an example of the phenomenon of being 'embattle[d] with structural limitations' (Archer, 2007, p.302), as there is no such long-term context they could embrace uncritically (Archer, 2003). The structural factors thus tend to act as limitations for achieving their cultural ideals.

In the flexibility discussion, where everybody contributed to the forum from various perspectives, she underlined the importance of 'equity', while supporting the idea of having a voice on 'how' and 'when' questions in the curriculum. She also mentioned about adding 'equity' to the title 'Curriculum for Excellence', while questioning whether the first 10 years of CfE have managed to foster equity. It could be observed that Amy's aspirations in curriculum making focused predominantly on equity.

She also emphasised the significance of access to good research and giving time for teachers to enable them to make the curriculum. As an individual who practised metareflexivity, Amy showed some insights about self-examination (Archer, 2007), especially on how score tests/exams are not adequate, and therefore she proposed something else:

Assessment of wellbeing, assessments which take account of added value rather than just standardised exam-measurable success, assessments of soft skills like co-operation and listening skills, empathy. Skills for learning, life and work which we say we value but then struggle to assess so give up on again. (Amy, Scotland) 
We could assert that how she formed her ideas, regarding the structural constraints at macro-level (e.g. assessment criteria), was associated with meta-reflexivity mode through being a social critic (Archer, 2003). The alignment between her concerns related to curriculum and what actually happens needed to be established, to nurture her modus vivendi and ultimately to prevent meta-reflexivity being displaced by the fractured modality.

\section{Fractured Reflexivity}

Fractured reflexivity is not a homogenous mode, according to Archer (2012). There are three sub categories: displaced, impeded and expressive reflexivity. Displaced reflexivity refers to the people who had a different dominant mode of reflexivity before adverse circumstances disabled them. Impeded reflexivity is related to not practising a dominant mode of reflexivity prior to the fractured modality whilst expressive reflexivity, which is close to near nonreflexivity, is having very limited internal conversations. In this section, we offer an example of displaced reflexivity, in the case of a teacher whose previous mode seemed to be inclined towards meta-reflexivity.

Kevin is a teacher with 30 years of experience in science, chemistry and biology. He was very interested in integrating research within his practice and he read quite widely (journal articles, social media, blogs, etc.) to help him inform his students' learning. Thus, he did not like being told to use particular methodologies (i.e. learning styles) with no basis in research. His personal power of mediating his way through the world seemed to be disabled by structural factors such as changes in policies, which he claimed lack evidence. For example, he explained:

My experience of CfE is one of bewilderment, fog, loss and a feeling of abandonment by leaders... They thought up a 'brilliant education experience', but thought that vision trumped pragmatism, resources, planning and capacity to deliver. (Kevin, Scotland)

It appeared that he had been trying to find a way to act which he considered best in his own context, but his 'self-puzzlement' (Archer, 2007, p.127) remained unsolved. Hence, his internal conversations served to intensify his personal distress, which often left him unable to direct purposeful actions to solve his problems (Archer, 2007). One exception, where he felt able to direct his actions, was adjusting assessments in Broad General Education (years Secondary 1-3), but he could not do the same for high stakes material in the Senior Phase (years S4-6), as it could be moderated. This demonstrates the constraining influence of structural factors. 
He seemed to be very knowledgeable about the policy and curriculum documents, which he thought lack coherence. As such, he quoted from different sources (for example the self-evaluation framework How Good Is Our School?, known as HGIOS) to illustrate how 'policy compliance' in educational decisions weakens teachers, resulting in a sense of powerlessness.

One could also argue that [HGIOS indicator] 3.1.4., 'Have high expectations of all learners', seems uncontestable, yet it leads on to a professional action of 'ensure learning tasks are varied, differentiated and devised to build confidence and promote progress of all learners, providing effective support and challenge' which extols differentiation and the use of a myriad of tasks that are impossible to plan for in a working week. (Kevin, Scotland)

It was observed that his deliberations could go around in circles, and this often led to anger and negativity, which rendered him unable to mediate his ideas to develop consistent actions. Structural constraints and the limited support he received appear to have contributed to the superseding of his former mode of meta-reflexivity. After a period of time of reflecting on his own reflections, he concluded that teachers have lost the artistry of curriculum making.

\section{Discussion}

The data illustrate the significance of context and the specific time period in which teachers act when looking at teacher mediation in curriculum making. We suggest that Archer's $(2003 ; 2007 ; 2012)$ modes of reflexivity provide a useful lens to explore how teachers navigate their ways through curriculum, while emphasising their context dependent, nondeterministic and multi-faceted nature. Nevertheless, it provides an opportunity to explore insights into how teachers make sense of and take decisions about the curriculum, even of a partial nature. These modes offer different opportunities for action and spaces to deal with unexpected consequences during or after curriculum reform. Based on the reflexivity research, agential responses can vary greatly 'from evasion to compliance, to strategic manipulation or subversion' (Archer, 2007, p.15).

Those who practise communicative reflexivity tend to create opportunities to get support and clear guidance from internal and external sources; interestingly, all such teachers in this research were from Wales. This potentially shows the tendency for these teachers to fulfil their needs for clearer and tangible guidance to navigate their worlds. It is also perhaps linked to the contextual factors in Wales, as the co-construction phase of the curriculum is currently on-going and at an early stage. This process could be further improved by providing 
more inclusive support and clear expectations as part of sense-making activities to prevent potential tendency to protect the status quo. This also supports Schwab's notion about the active engagement of real actors and locality as vital elements of participatory curriculum making (Schwab, 2009).

One individual, who tended to exhibit autonomous reflexivity, illustrated that having a clear sense of what he can control, being task-oriented and finding opportunities to create potential success appear to be key characteristics of this modality. We do not deny other factors which may contribute his way of mediating curriculum making practices, such as his previous experiences in SQA, where he actively constructed the curriculum. On the contrary, we would argue that these experiences may be influential on the development of his current dominant mode of reflexivity, as he takes responsibility for his own actions. In such cases, people may need more incentives to continue for further development (Brew et. al., 2017). Otherwise, practices may involve only auditing existing practices against learning outcomes (Priestley \& Minty, 2013).

Our data suggest that meta-reflexivity as a dominant mode - and relational mode was the most common among the teachers. This may not be surprising considering the valuable insights from Dewey (1938) and Stenhouse (1975) on the importance of teachers transforming cultural wisdom through inquiry. Most of the teachers stated that they would make their decisions based on their values, yet the structural and cultural factors (e.g. lack of time and resources) inhibit this process. Nevertheless, establishing equity for all and emphasising value-oriented decisions have been the prominent features as these teachers navigate their way through the curriculum. Brew and colleagues (2017) suggest that these people could be the most helpful ones in terms of policy implementation, as they tend to initiate an equitable reform through their criticism. We would argue that this may require adequate support mechanisms and constructive environments, which appear to be comparatively missing in most of the teachers' cases.

Fractured reflexivity presents other ways of mediating (or not) curriculum making practices. Our one case suggests that some reforms, which fail to provide adequate evidence and clarity, may indeed hinder the potential of some teachers, as it is the case for Kevin. On the other hand, it also appears that overcomplicating things and constant critique may lead to negativity, and often to non-purposeful actions. Changing circumstances are also significant in shaping how teachers are sometimes disabled from navigating their own pathways. We are 
clear that he has a great deal of knowledge on the relevant areas of research and policy, but this and his previous life experiences seem to intensify his distress, which in turn affects his navigation through curriculum making.

\section{Conclusion and Implications}

We posit that the reflexivity theory of Archer $(2003 ; 2007 ; 2012)$ provides a useful lens to explore what drives particular responses, in terms of different ways of mediating curriculum making practices. This is significant, because teachers' own sense making and decisionmaking processes, linked to curriculum, require further research.

What do the evidence and the discussions with regards to reflexivity say about the implications for theory, practice and policy in curriculum making? Starting with theory, this research makes an original contribution to the field of curriculum studies, by illustrating how a more nuanced exploration can be achieved by applying the modes of reflexivity. At this point, we consider the need for further elaboration of these modes, since these are complex constructs. As for practice at different layers, this research reiterates the importance of teachers' judgements and the interconnectivity of teacher and curriculum development (Stenhouse, 1975), and therefore we suggest the need for opportunities in professional learning, for example sense-making activities. This also sets the scene for engaging teachers in curriculum making practices, by emphasising the significance of context, time period (e.g. at the beginning or during the reform) and support. Since curriculum reforms tend not to be strongly informed by evidence (van den Akker, 2010), this research aims to provide empirical data oriented towards to teachers' curriculum making and how they mediate these processes, which in turn may create spaces to address the policy/practice interface.

A further implication of this research lies in the complex field of teacher professional education. The research suggests that a teacher's mode of reflexivity is important in shaping how the teacher responds to mandated reform. While previous research (e.g. Priestley et al., 2015) has been critical of reform policy that over-emphasised the importance of the individual teacher, thus neglecting the structural and cultural conditions that frame teachers' work, this research suggests that the individual is still an important factor in successful curriculum making, and moreover that this is about more than just enhancing teachers' professional knowledge or changing their mindsets towards reform. As the case of Kevin demonstrates, a teacher can be highly knowledgeable and exhibit views that are broadly supportive of the reform in question, and yet still be unable to mediate available resources 
Hizli Alkan, S. \& Priestley, M. (in press). Teacher mediation of curriculum making: the role of reflexivity. Journal of Curriculum Studies

effectively to realise the reform. In such cases, personal reflexivity is a strong factor, and it is theoretically possible to tailor teacher education to develop more constructive modes of reflexivity in such teachers. Similarly, as noted in respect of the Welsh context, it is important to tailor support for teachers that acknowledges the existence of different modes of reflexivity. This is not about labelling individuals; rather it is about acknowledging diversity of approaches, needs, etc. - and moving beyond one-size-fits-all approaches to teacher education and support for curriculum development. This research, in a limited way, signposts this potential, and points to the need for further, more comprehensive research in this important field.

\section{References}

Alvunger,D., Sundberg, D. \& Wahlström, N. (2017). Teachers matter - but how?. Journal of Curriculum Studies, 49 (1), 1-6.

Alvunger, D. (2018) Teachers' curriculum agency in teaching a standards- based curriculum, The Curriculum Journal, 29 (4), 479-498.

Arad Research and ICF Consulting. (2018). Formative evaluation of the pioneer school model: Final report. (Report No. 47/2018). Cardiff: Welsh Government. Retrieved from: https://gov.wales/statistics-and-research/formative-evaluationpioneer-schoolmodel/?lang=en

Archer, M. (2003). Structure, agency and the internal conversation. Cambridge: Cambridge University Press.

Archer, M. (2007). Making our way through the world. Cambridge: Cambridge University Press.

Archer, M. (2008). The internal conversation: Mediating between structure and agency: Full Research Report ESRC End of Award Report. Swindon: ESRC. (Report No., RES000-23-0349). Retrievedfrom:https://www.researchcatalogue.esrc.ac.uk/grants/RES000-23-0349/outputs/read/51ba9f9e-d6d4-4885-8bd0-8e611ab1bc04

Archer, M. (2012). The Reflexive Imperative in Late Modernity. Cambridge: Cambridge University Press.

Ball, S.J., Maguire, M. and Braun, A. (2012). How schools do policy: Policy enactments in secondary schools. London: Routledge 
Hizli Alkan, S. \& Priestley, M. (in press). Teacher mediation of curriculum making: the role of reflexivity. Journal of Curriculum Studies

Bloomer, M. (1997). Curriculum Making in Post-16 Education: The Social Conditions of Studentship. London: Routledge.

Bobbitt, F. (1924). How to Make Curriculum, Boston: Houghton Mifflin. Cited in Scott, D. (2008) Critical Essays on Major Curriculum Theorists. London: Routledge

Bobbitt, F. (2009). Scientific method in curriculum-making. In: D. J. Flinders \& S. J. Thornton (Eds.), Curriculum Studies Reader (3rd ed.), pp. 15-22. New York, NY: RoutledgeFalmer.

Brew, A., Boud, D., Lucas, L., \& Crawford, K. (2017). Responding to university policies and initiatives: the role of reflexivity in the mid-career academic. Journal of Higher Education Policy and Management, 39(4), 378-389.

British Educational Research Association [BERA] (2018) Ethical Guidelines for Educational Research (4th edition). London. Retrieved from https://www.bera.ac.uk/researchers-resources/publications/ethicalguidelines-foreducational-research-2018.

Burkhauser, M. A. \& Lesaux, N. K. (2017). Exercising a bounded autonomy: novice and experienced teachers' adaptations to curriculum materials in an age of accountability. Journal of Curriculum Studies, 49(3), 291-312.

Clark, B., and Dervin, J. (2014). Reflexivity in Applied Linguistics, Language and Intercultural Education. London: Routledge.

Coburn, C. E. (2005). Shaping teacher sensemaking: School leaders and the enactment of reading policy. Educational Policy, 19(3), 476-509.

Cuban, L. (1998). How schools change reforms: redefining reform success and failure. Teachers College Record, 99 (3), 453-477.

Deborah, L. B. \& Banister, E. M. (2012). Reflexivity. In Mills, A. J., Durepos, G. \& Wiebe, E. (2012) Encyclopedia of Case Study Research. Thousand Oaks: SAGE publications, Inc.

Dewey, J. (1938). Experience and Education. The Kappa Delta Pi Lecture Series. New York: Collier Books. 
Hizli Alkan, S. \& Priestley, M. (in press). Teacher mediation of curriculum making: the role of reflexivity. Journal of Curriculum Studies

Donaldson, G. (2011). Teaching Scotland's Future: Report of a review of teacher education in Scotland. Edinburgh: Scottish Government. Retrieved from: https://www.gov.scot/Publications/2011/01/13092132/0

Donaldson, G. (2015). Successful futures: Independent review of curriculum and assessment arrangements in Wales. OGL. Retrieved from: http://dera.ioe.ac.uk/22165/2/150225-successful-futures-en_Redacted.pdf

Drew V., Priestley, M. \& Michael, M. K. (2016). Curriculum development through critical collaborative professional enquiry. Journal of Professional Capital and Community, 1(1), 92-106.

Education Scotland (2016). Curriculum for excellence. Retrieved from: https://education.gov.scot/Documents/All-experiencesoutcomes18.pdf

Education Wales (2017). Education in Wales: Our national mission. Cardiff: Welsh Government. Retrieved from https://beta.gov.wales/sites/default/files/publications/2018-03/education-in-walesour-national-mission.pdf

Eynon, R., Fry, J. \& Schroeder, R. (2011). The Ethics of Internet Research. . In Fielding, N., Lee, R.M. \& Blank, G. (Ed.), The SAGE Handbook of Online Research Methods (pp. 22-41), Sage Publications.

Finlay, L., \& Gough, B. (2003). Reflexivity: A Practical Guide for Researchers in Health and Social Sciences. Cornwall: Blackwell Science.

Gaiser, T. J. (2008). Online focus groups. In N. Fielding, R. M. Lee \& G. Blank (Eds.), The SAGE handbook of online research methods (pp. 290-306), Sage Publications.

Hancock, M. E. (2017). The use of WordPress in online focus group studies. The Qualitative Report, 22(8), 2273-2280. Retrieved from https://nsuworks.nova.edu/tqr/vol22/iss8/12

Huizinga, T., Handelzalts, A., Nieveen, N. \& Voogt, J. M. (2014). Teacher involvement in curriculum design: need for support to enhance teachers' design expertise. Journal of Curriculum Studies, 46(1), 33-57. 
Hizli Alkan, S. \& Priestley, M. (in press). Teacher mediation of curriculum making: the role of reflexivity. Journal of Curriculum Studies

Kahn, P., Everington, L., Kelm, K., Reid, I., \& Watkins, F. (2017). Understanding student engagement in online learning environments: the role of reflexivity. Educational Technology Research and Development, 65(1), 203-218.

Kelly, A.V. (2004). The curriculum: Theory and practice. London: Sage Publications.

Kontovourki, S., Philippou, S. \& Theodorou, E. (2018). Curriculum making as professionalism-in-context: the cases of two elementary school teachers amidst curriculum change in Cyprus. The Curriculum Journal, 29(2), 257-276.

Lincoln, Y., \& Guba, E. G. (1985). Naturalistic inquiry. Newbury Park, CA: Sage.

Mason, J. (2002). Qualitative Researching, $2^{\text {nd }}$ edition. London: Sage Publications.

McCulloch, G. (2000). The politics of secret garden: Teachers and the school curriculum in England and Wales. In: Day, C., Fernandez, A., Hauge, T.E. and Møller (Eds.), The Life and Work of Teachers: International Perspectives in Changing Times. (pp. 2537). London, New York: Taylor Francis Group.

Mouzelis, N. (2007). Habitus and Reflexivity: Restructuring Bourdieu's Theory of Practice. Sociological Research Online, 12(6), pp.1-6.

Murray, P. (1997). Using Virtual Focus Groups in Qualitative Research. Qualitative Health Research, 7(4), pp.542-549.

Nieveen, N. \& Kuiper, W. (2012). Balancing curriculum and freedom in the Netherlands. European Educational Research Journal, 11(3), 357-368.

OECD (2018). The Future of Education and Skills: Education 2030. Paris: OECD

Old, A. (2015). The International Language of Edu-Platidues (Updated). Retrieved from: https://teachingbattleground.wordpress.com/2015/03/03/the-international-languageof-edu-platitudes-updated/

Pietarinen, J., Pyhältö, K., \& Soini, T. (2017). Shared sense-making in curriculum reform: Orchestrating the local curriculum work. Scandinavian Journal of Educational Research.

Priestley, M. \& Humes, W. (2010). The development of Scotland's curriculum for excellence: Amnesia and déjà vu. Oxford Review of Education, 36(3), 345-361. 
Priestley, M., Edwards, R., Miller, K. \& Priestley, A. (2012). Teacher agency in curriculum making: agents of change and spaces for manoeuvre. Curriculum Inquiry, 42(2), 191-214.

Priestley, M., \& Biesta, G. J. J. (2013). Introduction: The new curriculum. In M. Priestley \& G. Biesta (Eds.), Reinventing the curriculum: New trends in curriculum policy and practice (pp. 1-12). London: Bloomsbury Academic.

Priestley, M. \& Minty, S. (2013). Curriculum for excellence: 'A brilliant idea, but..', Scottish Educational Review, 45(1), 39-52.

Priestley, M. (2014). Curriculum regulation in Scotland: A wolf in sheep's clothing is still a wolf. European Journal of Curriculum Studies, 1(1), 61-68.

Priestley, M. \& Sinnema, C. (2014). Downgraded curriculum? An analysis of knowledge in new curricula in Scotland and New Zealand. The Curriculum Journal, Special Edition: Creating Curricula: Aims, Knowledge, and Control, 25(1), 50-75.

Priestley, M., Biesta, G. J. J. \& Robinson, S. (2015). Teacher agency: An ecological approach. London: Bloomsbury Academic.

Priestley, M. \& Philippou, S. (2018). Curriculum making as social practice: complex webs of enactment. The Curriculum Journal, 29(2), 151-158.

Pyhältö, K., Pietarinen, J. \& Soini, T. (2015). Teachers' professional agency and learning from adaption to active modification in the teacher community, Teachers and Teaching, 21(7), 811-830.

Pyhältö, K., Pietarinen, J., \& Soini, T. (2018). Dynamic and shared sense-making in largescale curriculum reforms in school districts. The Curriculum Journal, 29(2), 181200.

Ryan, M., \& Bourke, T. (2013). The teacher as reflexive professional: Making visible the excluded discourse in teacher standards. Discourse: Studies in the Cultural Politics of Education, 34(3), 411-423.

Schön, D. A. (1983). The reflective practicioner: How professionals think in action. United States of America: Basic Books Inc. 
Hizli Alkan, S. \& Priestley, M. (in press). Teacher mediation of curriculum making: the role of reflexivity. Journal of Curriculum Studies

Schwab, J.J. (2009) The Practical: A language for Curriculum. In: D. J. Flinders \& S. J. Thornton (Eds.), Curriculum Studies Reader (3rd ed.), pp. 123-137. New York: Routledge.

Scott, D. (2008). Critical Essays on Major Curriculum Theorists. London and New York: Routladge.

Scottish Executive (2004). A curriculum for excellence: The curriculum review group. Edinburgh, Scottish Executive. Retrieved from: https://www.gov.scot/Publications/2004/11/20178/45862feducation

Scottish Executive (2006). A curriculum for excellence: Progress and proposals. Edinburgh: Scottish Executive. Retrieved from: https://www.gov.scot/resource/doc/98764/0023924.pdf

Sinnema, C., \& Aitken, G. (2013). Trends in international curriculum development. In M. Priestley \& G.J.J. Biesta (Eds.), Reinventing the curriculum: New trends in curriculum policy and practice (pp. 141-164). London: Bloomsbury.

Sherin, M., \& Drake, C. (2009). Curriculum strategy framework: investigating patterns in teachers' use of a reform-based elementary mathematics curriculum. Journal of Curriculum Studies, 41(4), 467-500.

Soini, T., Pietarinen, J., \& Pyhältö, K. (2017). Shared sense making strategies in curriculum reform: District level perspective. Improving Schools, 21(2), 111-126.

Spillane, J. P. (1999). External reform initiatives and teachers' efforts to reconstruct their practice: The mediating role of teachers' zones of enactment, Journal of Curriculum Studies, 31(2), 143-175.

Stake. R. E. (2005). Qualitative case studies. In N. Denzin \& Y. Lincoln (Eds.), The Sage handbook of qualitative research (3rd ed.) (pp. 443-466). Thousand Oaks, CA: Sage Publications.

Stenhouse, L. (1975). An Introduction to Curriculum Research and Development. London: Heinemann.

Stewart, K. \& Williams, M. (2005). Researching online populations: the use of online focus groups for social research. Qualitative Research, 5(4), pp.395-416. 
Hizli Alkan, S. \& Priestley, M. (in press). Teacher mediation of curriculum making: the role of reflexivity. Journal of Curriculum Studies

Troyer, M. (2019). Teachers' adaptations to and orientations towards an adolescent literacy curriculum, Journal of Curriculum Studies, 51(2), 202-228.

Tyler, R. W. (1949). Basic Principles of Curriculum and Instruction. Chicago and London: The University of Chicago Press.

Van den Akker, J. (2003). Curriculum perspectives: An introduction. In J. van den Akker, W. Kuiper, \& U. Hameyer (Eds.), Curriculum landscapes and trends (pp. 1-10). Dordrecht: Kluwer.

Van den Akker, J. (2010). Building bridges: how research may improve curriculum policies and classroom practices. In Stoney, S. M. (Ed.), Beyond Lisbon 2010: perspectives from research and development for education policy in Europe (CIDREE yearbook 2010), (pp. 175-196). Slough: National Foundation for Educational Research.

Wallace, C. S. \& Priestley, M. (2017). Secondary science teachers as curriculum makers: Mapping and designing Scotland's new curriculum for excellence. Journal of Research in Science Teaching, 54(3), 324-349.

Welsh Government (2017). A new curriculum for Wales: The story so far. Retrieved from: https://www.crickhowell-hs.powys.sch.uk/wp-content/uploads/2017/08/A-NewCurriculum-for-Wales-The-Story-So-Far-072017.pdf

Wheelahan, L. (2010). Why knowledge matters in curriculum: A social realist argument. London: Routledge.

Willis, J., Crosswell, L., Morrison,C., Gibson, A. \& Ryan, M. (2017). Looking for leadership: the potential of dialogic reflexivity with rural early-career teachers, Teachers and Teaching, 23(7), 794-809.

Wimalasena, L. (2017). Reflexivity and women's agency: a critical realist morphogenetic exploration of the life experience of Sri Lankan women. Journal of Critical Realism, 16(4), pp.383-401.

Yates, L. \& Collins, C. (2010). The absence of knowledge in Australian curriculum reforms. European Journal of Education, 45(1), 89-102.

Young, M. \& Muller, J. (2010). Three Educational Scenarios for the Future: lessons from the sociology of knowledge. European Journal of Education, 45(1), 11-27. 